\title{
Posterior endoscopic cervical foramiotomy and discectomy: clinical and radiological computer tomography evaluation on the bony effect of decompression with 2 years follow-up
}

\author{
Pang Hung Wu $\mathbf{W}^{1,2} \mathbb{D} \cdot$ Hyeun Sung Kim ${ }^{1}$ (D) Yeon Jin Lee ${ }^{1} \cdot$ Dae Hwan Kim $^{1} \cdot$ Jun Hyung Lee Kyung-Hoon Yang $^{1}$. \\ Harshavardhan Dilip Raorane ${ }^{1} \cdot$ II-Tae Jang ${ }^{1}$
}

Received: 9 May 2020 / Revised: 16 September 2020 / Accepted: 10 October 2020 / Published online: 19 October 2020

(c) The Author(s) 2020

\begin{abstract}
Purpose Cervical radiculopathy is a common disabling cervical spine condition. Open anterior and posterior approaches are the conventional surgical treatment approaches with good clinical outcomes. However, the soft tissue damage in these procedures can lead to increase perioperative morbidity. Endoscopic spine surgery provides more soft tissue preservation than conventional approaches. We investigate the radiological and clinical outcomes of posterior endoscopic cervical foraminotomy and discectomy.

Methods A prospective clinical and radiological study with retrospective evaluation were done for 25 patients with 29 levels of cervical radiculopathy who underwent posterior endoscopic cervical discectomy from November 2016 to December 2018. Clinical outcomes of Visual Analogue Scale, Neck Disability Index and MacNab's score were evaluated at pre-operative, post-operative 1 week, 3 months and final follow-up. Preoperative and post-operative final follow-up flexion and extension roentgenogram were evaluated for cervical stability assessment. Pre-operative and post-operative computer tomography cervical spine evaluation of foraminal length in ventro-dorsal, cephalad-caudal dimensions, sagittal foraminal area and using 3D CT reconstruction coronal decompression area were done.

Results Twenty-nine levels of cervical radiculopathy underwent posterior endoscopic cervical decompression. The mean follow-up was 29.6 months, and the most common levels affected were C5/6 and C6/7. There was a complication rate of $12 \%$ with 2 cases of neurapraxia and one case of recurrent of prolapsed disc. There was no revision surgery in our series. There was significant clinical improvement in Visual Analogue Scale and Neck Disability Index. Prospective comparative study between preoperative and final follow-up mean improvement in VAS score was 5.08 \pm 1.75 , and NDI was 45.1 \pm 13.3 . Ninety-two percent of the patients achieved good and excellent results as per MacNab's criteria. Retrospective evaluation of the radiological data showed significant increments of foraminal dimensions: (1) sagittal area increased $21.4 \pm 11.2 \mathrm{~mm}^{2}$, (2) CT Cranio Caudal length increased $1.21 \pm 1.30 \mathrm{~mm}$ and (3) CT ventro-dorsal length increased $2.09 \pm 1.35 \mathrm{~mm}$ and (4) 3D CT scan reconstruction coronal decompression area increased $536 \pm 176 \mathrm{~mm}^{2}, p<0.05$.

Conclusion Uniportal posterior endoscopic cervical foraminotomy and discectomy are safe, efficient and precise choreographed set of technique in the treatment of cervical radiculopathy. It significantly improved clinical outcomes and achieved the objective of increasing in the cervical foramen size in our cohort of patients.
\end{abstract}

Keywords Cervical radiculopathy $\cdot$ Endoscopic spine surgery $\cdot$ Posterior endoscopic cervical discectomy $\cdot$ Posterior endoscopic cervical foraminotomy $\cdot$ Cervical spine $\cdot$ Cervical endoscopy

\section{Introduction}

Hyeun Sung Kim and Pang Hung Wu contributed equally to this work as first authors.

Hyeun Sung Kim

neurospinekim@gmail.com

Extended author information available on the last page of the article
Cervical radiculopathy is a common cervical spine condition which is potentially disabling with nerve root dysfunction [1]. Increasing prevalence of sedentary occupation with overuse of computer technology, laptops and handheld devices may lead to higher incidence of cervical 
radiculopathy and cervical degeneration in the long run due to poor neck posture. At least 6 weeks of conservative therapy is recommended for of cervical radiculopathy without myelopathy [1]. The symptoms of cervical radiculopathy may subside as the inflammatory cytokines released from the prolapsed intervertebral disc abates over time. However, mechanical compression may remain despite symptomatic management. Time to recovery ranged from 2 to 3 years in $83 \%$ of the patients [2]. A proportion of patients suffer significant disabling symptoms despite conservative management [2]. Anterior approaches treatment options such as cervical discectomy and fusion (ACDF) and cervical artificial disc replacement (ADR) are popular treatment options for cervical radiculopathy [3]. However, it involves sacrificing an intervertebral disc in the process of increasing the foraminal height and decompressing the foramen. Adjacent segment disease and pseudoarthrosis and being the commonest postoperative complications of anterior cervical surgery with an overall complication rate of anterior cervical surgery ranges from 13.2 to $19.3 \%$ [4]. Posterior cervical foraminotomy (PCF) has the advantage of motion preservation from conservation of the intervertebral disc and is a popular alternative to ACDF and ADR with good clinical results [5-7]. However, there is potential significant perioperative morbidity from neck pain and wound issues in conventional open cervical foraminotomy which limits the enthusiasm of this treatment option. The development endoscopy started with addressing lumbar spinal issues had evolved to provide solutions for the cervical spine [8]. It has the advantage of being a minimally invasive technique which conserves soft tissue, while achieving cervical foraminal decompression and discectomy for prolapsed intervertebral disc and foraminal stenosis [8-10]. It may avoid excessive resection of facet which can lead to instability of cervical spine [11]. There is paucity of literature on radiological evaluation of the amount of foramen decompression achieved by posterior endoscopic cervical decompression by foraminotomy and/or discectomy (PECD). There are also limited number of studies on the midterm clinical outcomes of patients who underwent PECD. The purpose of this study was to determine our working hypothesis that: (1) there would be a significant increment in foramen size after PECD and (2) there would be a corresponding sustained improved clinical outcomes in patients who underwent PECD at 2 years. In this study, we prospectively followed up a cohort of patients who underwent uniportal posterior full endoscopic cervical decompression by foraminotomy and discectomy for 2 years and retrospectively evaluated their radiological and clinical outcomes.

\section{Materials and methods}

\section{Patients' demographics}

This clinical study was reviewed by institutional review board of Nanoori Hospital, Seoul, Republic of Korea. The informed consent was obtained from all patients participated in study.

From November 2016 to December 2018, 25 patients presented with cervical radiculopathy accounted for 29 levels of uniportal posterior endoscopic cervical decompression (PECD) surgeries in our institute. We included patients who presented with unilateral intractable cervical radiculopathy and failed conservative treatment for more than 6 weeks. They had concordant magnetic resonance imaging finding of (1) unilateral soft cervical intervertebral disc herniation with $2 / 3$ of the bulk of cervical intervertebral disc material being lateral to the lateral margin of the thecal sac on MRI axial view and/or (2) cervical nerve root compression by cervical foraminal stenosis contributed by bulging lateral degenerative disc, hypertrophy in uncoverterbral joint and/or facet joint. We excluded patients with contraindications for posterior endoscopic cervical decompression: (1) calcified central disc, (2) instability of cervical spine, (3) significant cervical kyphosis of more than $10^{\circ}$, (4) advanced cervical myelopathy and (5) predominant axial neck pain. We also excluded patients with psychiatric comorbidities. The demographic variables examined were the following: age, sex, diagnosis levels of decompression, duration of surgery and duration of follow-up.

\section{Outcomes measure}

There was a standardized prospective follow up protocol at postoperative 1 week, 3 months, 6 months, 1 years and 2 years. As patients entered the study at different time points, we retrospectively analyzed clinical data collected at postoperative 1 week, 3 months and final follow up. Each follow-up consisted of history taking, clinical examination and answering of clinical questionnaires. Clinical data of Visual Analogue Scale (VAS) [12] and Neck Disability Index ( NDI) [13] from preoperative, 1 week postoperative, 3 months post-operative and final follow-up as well as MacNab's Criteria [14] for pain relief were collected prospectively. An anteroposterior and lateral cervical roentgenogram were done in each visit. At follow-up of 6 months onwards, flexion and extension films assessment were added. The clinical notes data were analyzed by 2 experienced Korean Spine Surgeons (YJL and DHK) who were not involved in the care of the study subjects. 
Post-operative complications, any recurrence of the same or adjacent levels, reoperations and neurological deficits were documented. Workstation software (Infinitt, inc, Seoul, Korea) was used for radiological variables measurement by 3 experienced spine surgeons (PHW, YJL, DHK) who were not involved in management of the study subjects. Preoperative computer tomography (CT), magnetic resonance imaging (MRI) and plain roentgenogram were obtained in all cases. Instability was defined as motion $>3 \mathrm{~mm}$ at the operative segment or any adjacent segments on cervical dynamic XR imaging [15]. MRI was assessed for the cause of cervical radiculopathy. The position and size of disc, uncal vertebral hypertrophy and foraminal stenosis were noted. CT data comparisons were made from images obtained preoperatively and 1 day post operatively in both sagittal and coronal parameters. We used INFINITT PACS M6 Version (INFINITT Healthcare Corporation, Seoul, Republic of Korea) for evaluation of the images. The comparison was made on the preoperative and post-operative sagittal area, cranio-caudal length and ventro-dorsal length of cervical foramen. We did not measure axial CT cut foramen changes due to significant variability of dimensions contributed in part to the complex, oblique orientation of the cervical neuroforamen with only fair interrater reliability. We measured the foraminal parameters at the most medial sagittal cut of CT cervical spine that could show both the pedicles of cephalad and caudal vertebra as well as superior and inferior articular facet for evaluation. If articular facet was absent or disrupted postoperatively in the corresponding cut, we evaluated the structure and shape of the pedicles to determine the corresponding sagittal cut (Fig. 1). Cranial-caudal length (CCL) was measured from the highest point of the foramen to the lowest point of the foramen in the same corresponding cut in pre- and post-operative CT scan. Preoperative ventro-dorsal length (VDL) was measured by connecting the most dorsal part the intervertebral disc space at the posterior vertebral body margin to the anterosuperior tip of the superior articular process of caudal vertebra. In the corresponding postoperative CT cut, ventro-dorsal length was measured from the most posterior bony structure of either cephalad or caudal vertebra end plate or uncal vertebral joint to the most anterior part of the superior articular facet of caudal vertebra, if the superior articular process in the corresponding cut was absent or disrupted after decompression, we marked 2 points on sclerotic margin of the remnant facets and determined the midpoint of the line connecting these 2 sclerotic margin points. The post-operative ventro-dorsal distance was measured between this midpoint to the most dorsal part of mid intervertebral disc space at the posterior vertebral body margin (Fig. 2). The sagittal foraminal area (SFA) was calculated with our software through points that marked the bony landmarks around the foramen and the defined posterior margin as described in the pre and postoperative CT scan (Fig. 3). 3D reconstructed CT scan coronal foraminal area (CCA) assessment was compared between pre-operative and post-operative day one images.

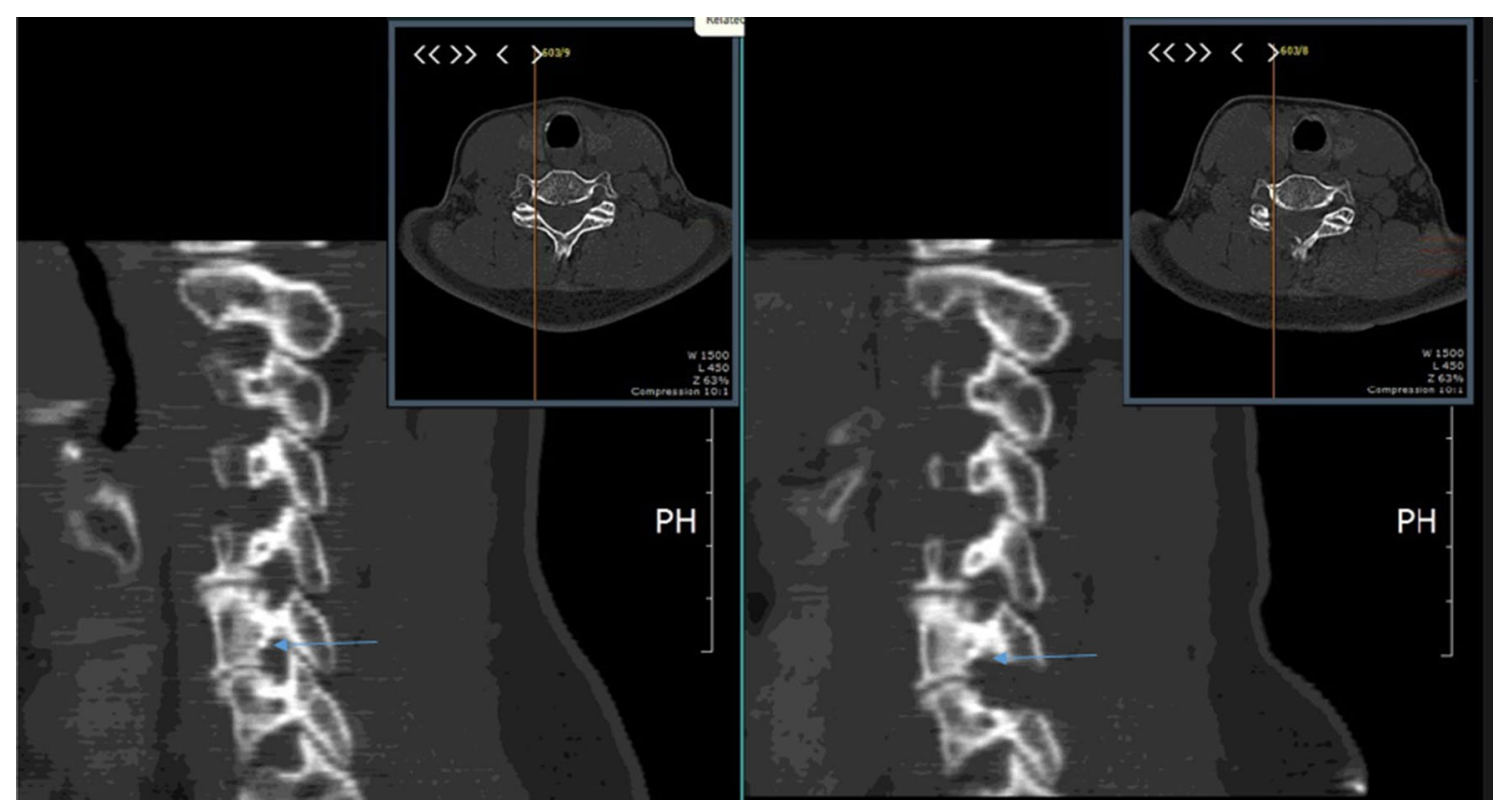

Fig. 1 Sagittal cut used for measurement of the foraminal parameters pre-operative figure (left) was compared with post-operative figure (right). We used the most medial sagittal cut that could show both the pedicles of cephalad and caudal vertebra as well as superior and inferior articular facet for evaluation. If articular facet was absent or disrupted postoperatively in the corresponding cut, we evaluated the structure and shape of the pedicles to determine the corresponding sagittal cut 


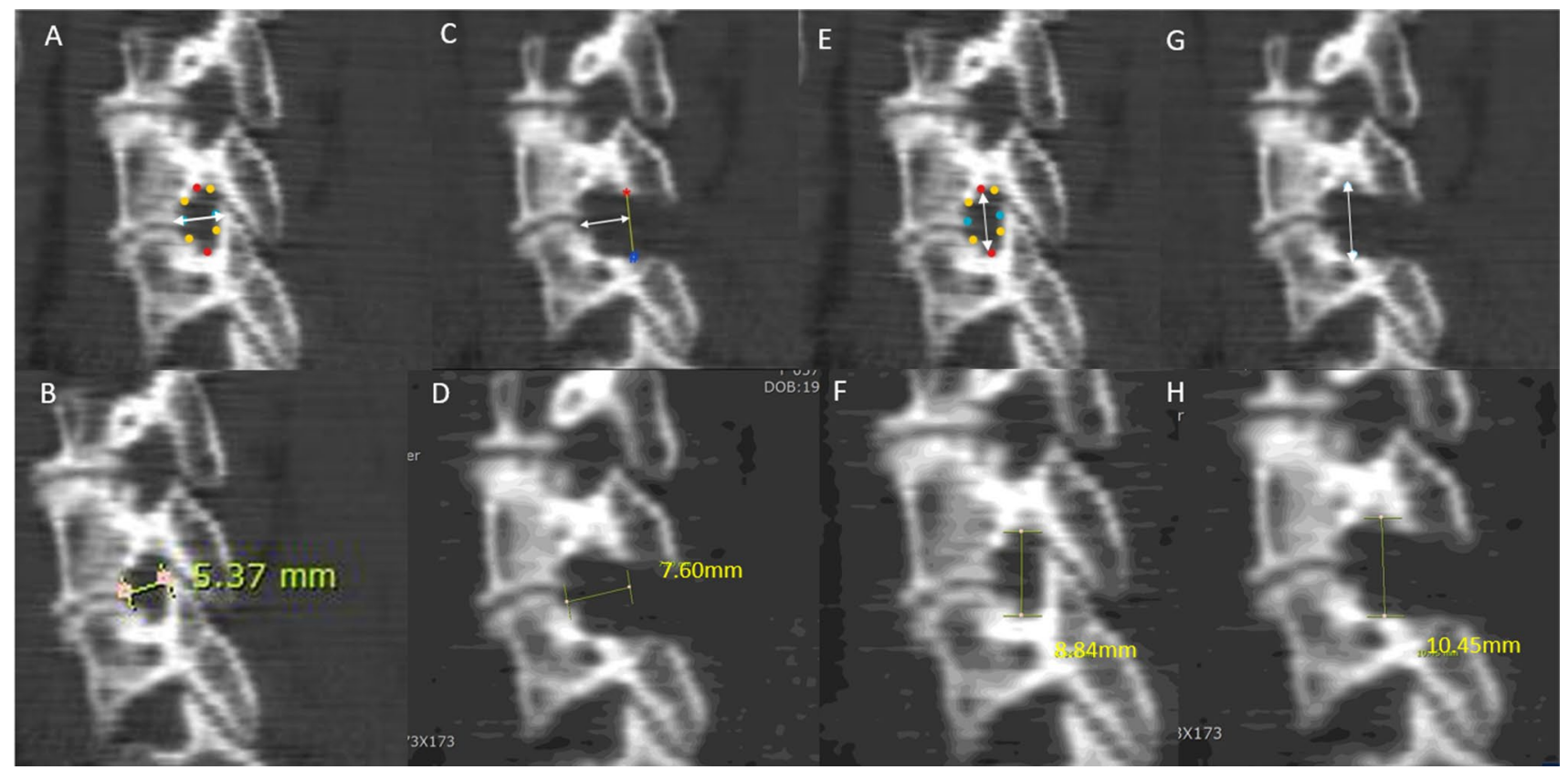

Fig. 2 Measurement of cranial-caudal length (CCL) and ventro-dorsal length (VDL) of the foramen pre- and post-operative CT sagittal cuts. a The ventro-dorsal length was measured connecting the dorsal part the intervertebral disc space on the posterior vertebral body margin to the anterosuperior tip of the superior articular process, measured as $5.37 \mathrm{~mm}$ as shown in b. c Measurement of the ventrodorsal length after decompression in the corresponding cut, CT scan was taken one day postoperatively, the facet joint was disrupted as expected, we use the points between sclerotic margin of facet of the

We used the 3D coronal reconstruction CT scan cut which showed the direct posterior view of the cervical spine as demonstrated by symmetrical bilateral caudal lamina morphology on the same cut. Pre-operative value of 3D reconstructed CT scan was standardized as $0 \mathrm{~mm}^{2}$, and post-operative area was measured by extrapolation of the area of decompression (Fig. 4).

\section{Definition of V-point in posterior endoscopic cervical foraminotomy and discectomy}

"V" point is defined as junction of confluence of cephalad and caudal laminofacet which has a $\mathrm{V}$ shape configuration [16] (Fig. 5a).

\section{Description of technique}

\section{Posterior endoscopic cervical foraminotomy (Fig. 5)}

All patients underwent general anesthesia and were positioned prone on Wilson frame with shoulder strapped and neck flexed in a slight reverse Trendelenburg position using 3 points plaster traction technique on head, shoulder and remnant facets as shown by red and blue dot, midpoint of the line was drawn to connect these 2 points and the distance from that point to the most dorsal part the intervertebral disc space on the posterior vertebral body margin. We measured the ventrodorsal distance $7.60 \mathrm{~mm}$ in this case. e The cranial caudal distance was measured from most superior aspect of the foramen to the most interior aspect of the foramen. It is measured as $8.84 \mathrm{~mm}$ in this case $\mathbf{f}$ and postoperative cranial caudal distance was 10.45 ( $\mathbf{g}$ and $\mathbf{~ h}$ )

back without use of Mayfield to increase interlaminar space of cervical spine [17]. Face was positioned in a commercially anesthesia pillow foam supporting bony prominence with space created for eyes, nose and mouth. The head attachment was tilted down slightly allowing cervical spine flexion and secured with plaster. Arms are padded and tucked longitudinally next to the patient. The anterior superior iliac spine and knees are padded, and hips and knees were flexed slightly. Both the shoulders were strapped to pull down the shoulder slightly without pressure on the brachial plexus and strapped on the back to reduce skin fold in the operating field. We did not use neuromonitoring during any of the procedures. Skin marking was done under guidance of anteroposterior (AP) and lateral view cervical fluoroscopy. We aimed for the lateral margin of interlaminar space and medial border of facet joint junction (the " $\mathrm{v}$ " point due to the $\mathrm{V}$ shape appearance on the confluence of the medial junction of superior and inferior facet) on AP view. Fluoroscopic lateral view was performed to confirm facet joint of the correct level. A transverse $8 \mathrm{~mm}$ incision was made at the "v" point and obturator was inserted and docked, tip position was confirmed with fluoroscopy. A $30^{\circ}$ viewing angle, 7.3 outer diameter, and $4.7 \mathrm{~mm}$ working channel (Joimax 
Fig. 3 Measurement of sagittal foraminal area (SFA).aThe margins of the foramen preoperatively were marked by dots. b Sagittal foraminal area was measured as $36.2 \mathrm{~mm}^{2}$ by Infinitti pacs software. $\mathbf{c}$ The margins of the foramen were marked by dots post decompression. The absent anterosuperior area of superior articular process was represented as the midpoint between the sclerotic margins of the facet joint as shown. d Sagittal foraminal area was increased to $64.2 \mathrm{~mm}^{2}$ as measured by Infinitti software

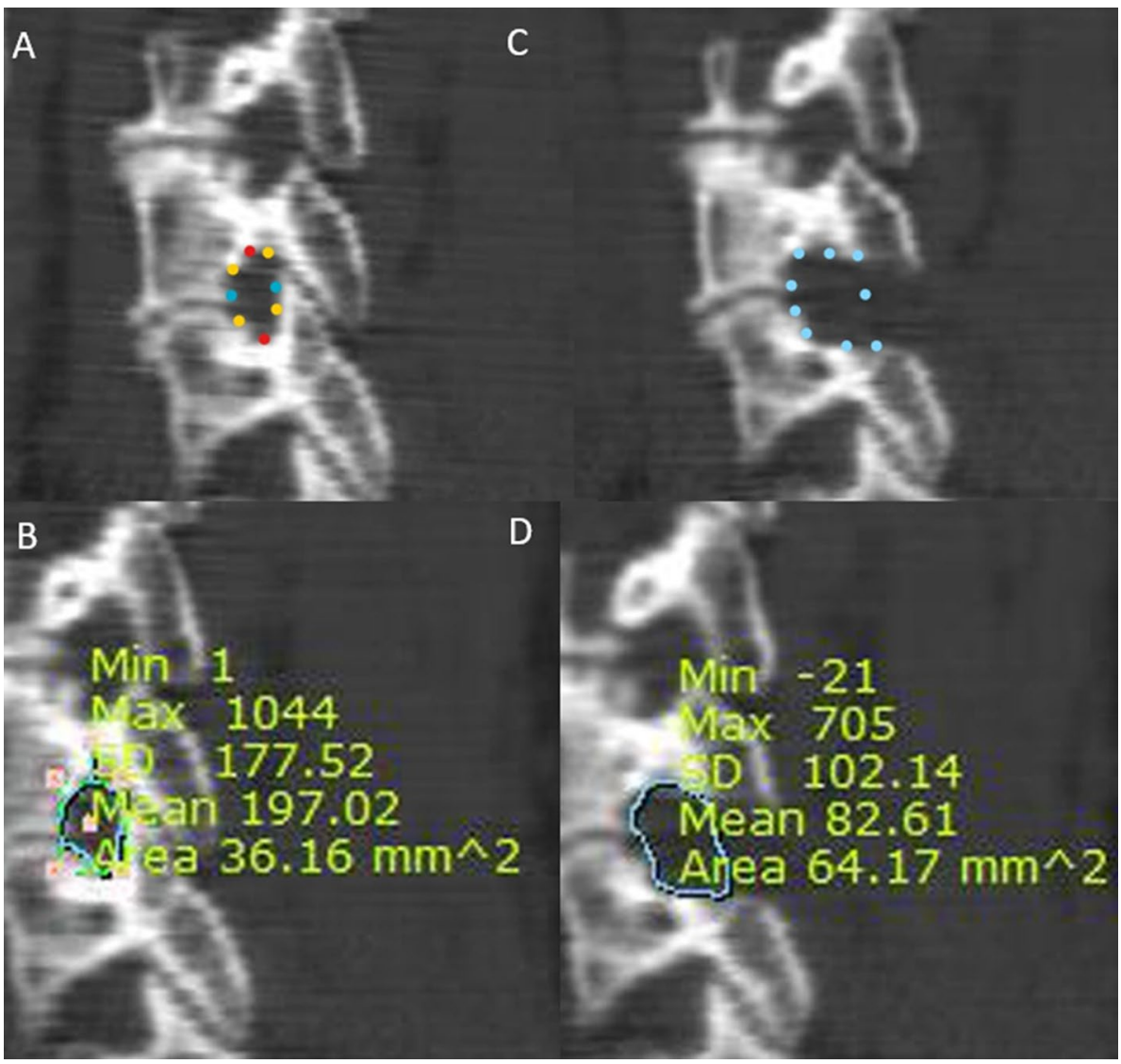

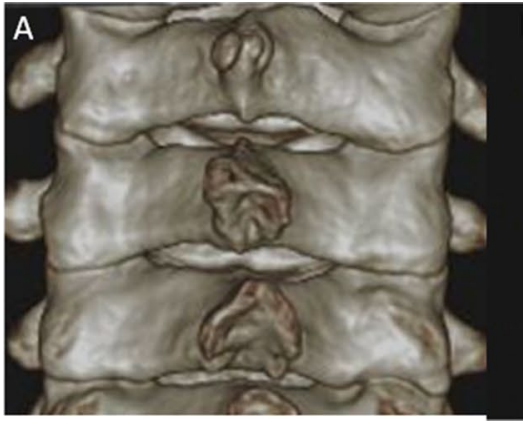

B

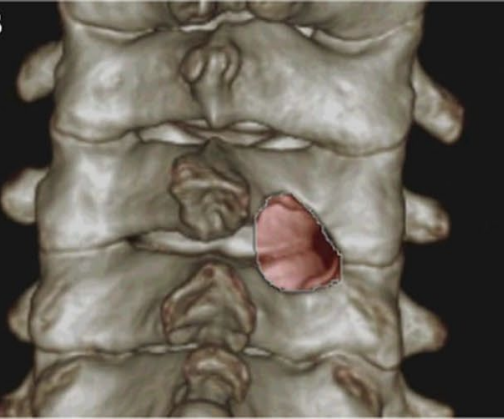

C

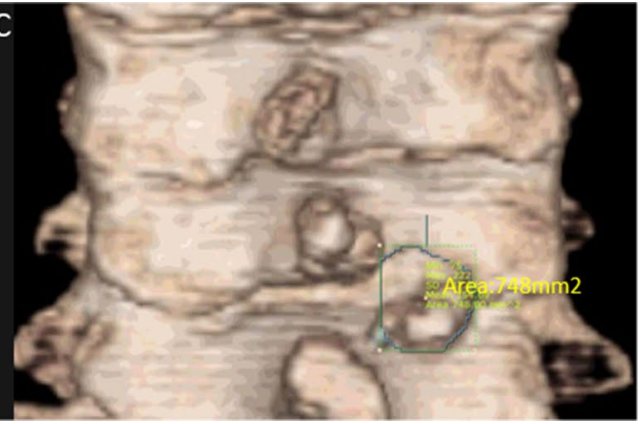

Fig. 4 a Preoperative 3D CT reconstructed scan of coronal view which we set as $0 \mathrm{~mm}^{2}$ decompression to standardize measurements. b The area of foraminotomy at left C5/6 was marked by red region.

$\mathrm{GmbH}$, Karlsruhe, Germany) was used for the procedure under continuous normal saline irrigation of pressure of $25 \mathrm{~mm} \mathrm{Hg}$. Hemostasis and soft tissue dissection were done with the radiofrequency probe (Ellman's bipolar radiofrequency electrocoagulator-Elliquence, Baldwin, New York, USA) and endoscopic forceps. Once V point was identified and confirmed on fluoroscopy, medial aspect of lateral mass and facet joint was drilled with a long straight high speed drill (Primado High-Speed Drill System-NSK, Nakanishi, Japan) to create a working window depending on the size of c The 3D reconstructed CT scan coronal foraminal area (CCA) after foraminotomy was measured as $748 \mathrm{~mm}^{2}$ on infinitti pacs system

herniated material and degree of foraminal stenosis. Typically $3-5 \mathrm{~mm}$ in diameter of bone was removed from lateral inferior aspect of upper lamina followed by about $3 \mathrm{~mm}$ of the medial inferior portion of inferior articular facet from the lamina-facet border("V" point) to gain access to the nerve root [18]. We then asked anesthetist to tilt patient away from surgeon to drill the medial superior aspect of superior articular facet of caudal vertebra lying on dorsal aspect of the nerve root; it would lead to the proximal portion of nerve root situated superior to the pedicle of caudal vertebra. After 


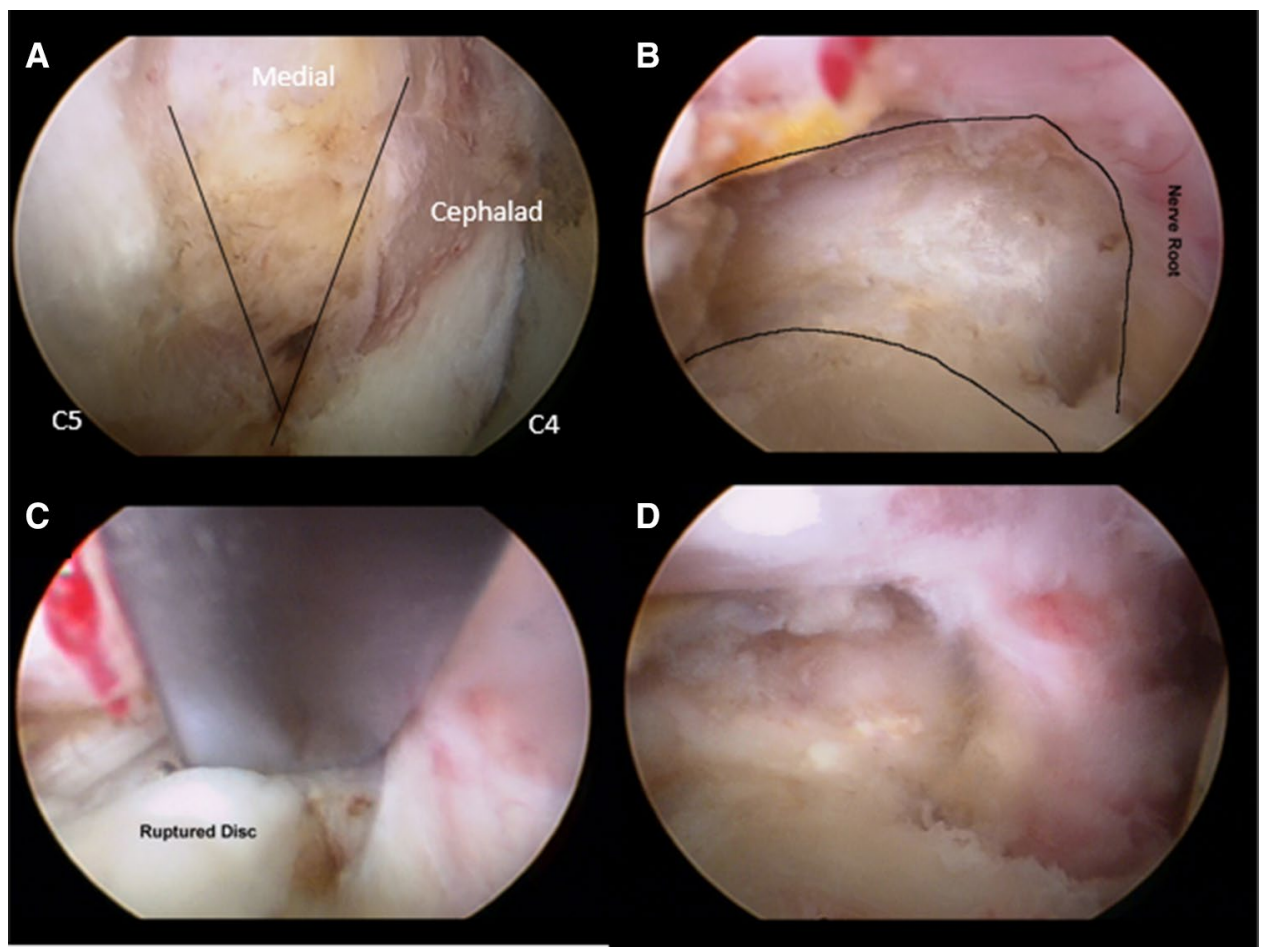

Fig. 5 Right $\mathrm{C} 4 / 5$ posterior endoscopic cervical decompression. a Identification of the "V" point which was marked by 2 black lines showing the margin of inferior margin of laminofacet junction of right $\mathrm{C} 4$ and superior margin of laminofacet junction of right $\mathrm{C} 5$. b After further drilling on the "V" point and decompression the nerve root underneath $\mathrm{C} 5$, upper black line marked the margin of the spinal cord and nerve root, lower black line marked the pedicle margin.

posterior foraminotomy was completed, we inspected the exiting nerve root and lateral third of spinal cord; both of which were closely related to the pedicle of caudal vertebra. This marked the completion of "V" point foraminotomy.

\section{Posterior cervical disectomy with neural retraction}

After foraminotomy was completed, the working channel was advanced and rotated with open beveled facing away from the axilla of the spinal cord and exiting nerve root. We retracted the exiting nerve root gently in cephalad or caudal direction depending on its relationship with the intervertebral disc and exposed the underlying prolapsed disc fragment. There was not any retraction of the spinal cord to avoid significant neurological sequelae. Endoscopic forceps and Kerisson rongeurs were used to retrieve the prolapsed disc fragment. Radiofrequency was used to provide hemostasis and gentle release of the adhesion of the neural elements to disc facilitating the retrieval of the prolapsed disc. Uncovertebral hypertrophy was taken down with a cutter or a drill. The pedicle was left intact. Final inspection of neural elements was done to assess completeness of decompression as evidenced by pulsatile neural elements c Deeper insertion of endoscope below the neural elements reveal margin of $\mathrm{C} 5$ vertebra and the intervertebral disc with the working cannula retracting the right $\mathrm{C} 5$ nerve root out of harms' way, the ruptured herniated disc was found in the axilla of right $\mathrm{C} 5$ nerve root. Figure 5D: Pulsating nerve root under irrigation fluid noted of right C5 after herniated disc removed from right C5 nerve root

under irrigation fluid. Drain was inserted and closed in layers with dermabond to skin.

\section{Statistical analysis}

Data were analyzed with SPSS version 18 statistical analysis software (IBM Corporation, New York). The continuous variables were expressed as mean and standard deviation (SD). Paired $t$ test was used for analysis of clinical visual analogue scale (VAS), Neck Disability Index (NDI) measured at preoperative, 1 week post-operative, 3 months post-operative and final follow-up. The paired $t$ test was also used for comparison of pre-operative and post-operative CT scan results of sagittal area, cranio-caudal length, and ventro-dorsal length as well as $3 \mathrm{D}$ reconstructed posterior decompression area. Pearson correlation analysis was performed to analyze the correlation between 2 continuous variables. A value of $(p<0.05)$ considered significant. 


\section{Results}

\section{Baseline demographics and operative data}

From November 2016 to December 2018, 29 levels of uniportal posterior endoscopic cervical decompression (PECD) were performed in 25 patients. 4 patients had 2 levels surgery, and 21 patients had single level cervical spine surgery. 3 patients had cervical stenosis accounting for 4 levels of endoscopic cervical foraminotomy performed, while 22 patients had cervical disc herniations accounting for 25 levels of endoscopic cervical foraminotomy and discectomy performed. The mean and standard deviation for follow up of PECD was $29.6 \pm 8.5$ months. The mean age was $51.8 \pm 8.9$ years. Overall most common levels of cervical radiculopathy were C5/6 (31.0\%) and C6/7 (55.2\%). Male patients represented $64 \%$ of the patients' cohort. Duration of surgery was 52.6 (40-65) min. There was no statistical difference in outcomes affected by sex and age (Table 1).

\section{Clinical outcomes}

The complication rate of PECD was $12 \%$ with 2 cases of motor deficits which had resolved within 1 year without revision and one patient had recurrence of symptoms due to prolapsed disc at the same level which was treated conservatively. Of these 3 cases, one patient who underwent C5/6 and C6/7 decompression had postoperative Medical Research Council grade 3 motor weakness of right C5. His power recovered to grade $4+$ on final follow-up at 24 months.
Another patient who underwent left C6/7 decompression had MRC grade 4 motor weakness of left $\mathrm{C} 7$ myotomes after surgery. Her power recovered to MRC grade 5 after 1 year. There was one case of recurrence of left $\mathrm{C} 6 / 7$ prolapsed disc after 2 years which was treated conservatively. There was no reoperation or revision in this cohort of patients. In this PECD cohort, there was significant improvement in preoperative, 1 week post-operative, 3 months post-operative and final follow-up VAS with mean and standard deviation were $7.28 \pm 1.25,3.36 \pm 0.76,2.64 \pm 1.11$ and $2.32 \pm 1.35$, respectively, $p<0.05$. NDI score also showed significant improvement with preoperative, 1 week post-operative, 3 months post-operative and final follow-up mean and standard deviation for were $71.5 \pm 8.67,30.8 \pm 6.43,27.7 \pm 8.87$ and $26.4 \pm 11.2$, respectively, $p<0.05$ (Fig. 6). MacNab score showed $92 \%$ ( 23 out of 25 patients) with good and excellent results, with 1 fair and 1 poor result patients were coincidentally the ones who suffered postoperative neuropraxia (Table 1).

\section{Radiological outcomes}

Flexion and extension roentgenograms were done at preoperative period to rule out instability. Postoperative flexion and extension roentgenogram at final follow-up were analyzed which showed no instability of the cervical spine in this cohort of patient.

Radiological outcomes evaluation in PECD cohort showed that there was statistical significant increase in foraminal dimensions in postoperative CT scan as compared to pre-operative $\mathrm{CT}$ scans. The mean and standard deviation

Table 1 Basic Demographics, Clinical and Radiological parameters of our PECD cohort data

\begin{tabular}{lllll}
\hline & Mean & SD & $p$ value & Remarks \\
\hline Age & 51.8 & 8.9 & & \\
Levels & & & & One C4/5, nine C5/6, 16 levels C6/7, one C7/T1 \\
Sex & & & & \\
Follow up period & 29.6 & 8.5 & & 4 Foraminal stenosis, 21 prolapsed intervertebral disc \\
Diagnosis & & & & \\
Increase in CT sagittal area $\left(\mathrm{mm}^{2}\right)$ & 21.483 & 11.186 & $<0.05$ & \\
Increase in 3D CT posterier area of decompres- & 536.586 & 175.923 & $<0.05$ & \\
$\quad$ sion (mm ${ }^{2}$ ) & & & & \\
Increase in length (cranial to caudal) $\left(\mathrm{mm}^{2}\right)$ & 1.20724 & 1.29634 & $<0.05$ & \\
Increase in length (ventral to dorsal) $\left(\mathrm{mm}^{2}\right)$ & 2.09724 & 1.35066 & $<0.05$ & \\
VAS improvement at 1 week & 4.040 & 1.098 & $<0.05$ & \\
VAS improvement at 3 months & 4.760 & 1.589 & $<0.05$ & \\
VAS improvement at final follow up & 5.080 & 1.754 & $<0.05$ & \\
NDI improvement at 1 week & 40.720 & 9.307 & $<0.05$ & \\
NDI improvement at 3 months & 43.800 & 11.811 & $<0.05$ & \\
NDI improvement at final follow up & 45.120 & 13.330 & $<0.05$ & 1 poor, 1 fair, 17 good, 6 excellent \\
MacNab's criteria & & &
\end{tabular}



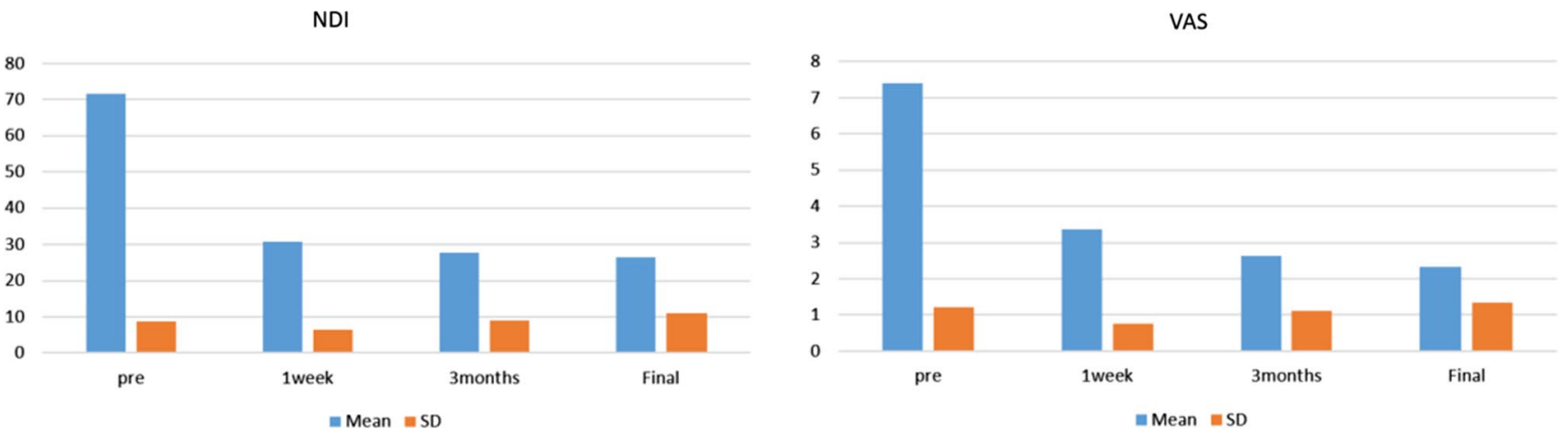

Fig. 6 Graphic representation of the mean and standard deviation (SD) for Neck Disability Index (NDI) and Visual Analogue Scale (VAS) in our cohort of patients

of the increments were (1) sagittal foraminal area (SFA) increased $21.5 \pm 11.2 \mathrm{~mm}^{2}$, (2) CT cranio-caudal foraminal length (CCL) increased $1.21 \pm 1.30 \mathrm{~mm}$ and (3) CT ventrodorsal foraminal length (VDL) increased $2.10 \pm 1.35 \mathrm{~mm}$ and (4) 3D CT scan reconstruction coronal view decompression area (CCA) increased $537 \pm 176 \mathrm{~mm}^{2}, p<0.05$. (Table 1).

\section{Pearson correlations analysis of continuous variables}

The continuous variables such as age, sagittal foraminal area (SFA), 3D CT coronal area (CCA), cranial-caudal Length (CCL), ventro-dorsal length (VDL), VAS and ODI were analysed using Pearson correlations analysis. We found statistical significant increment radiological correlations of SFA with CCA, CCL and VDL and clinical parameters of VAS and ODI. There were no statistical significant radiological correlations in CCA with CCL and VDL. There was no significant correlations between clinical outcomes with foraminal dimensions (Table 2).

A case example was shown in Fig. 7.

\section{Discussion}

While most of the patients who suffered from cervical radiculopathy were treated with conservative management. A good proportion of them failed conservative treatment and fulfilled the indications for surgery [19]. While anterior based procedures such as ACDF and ADR had demonstrated good clinical outcomes, these procedures sacrifice the intervertebral disc in order to achieve their objective of decompression. Invariably affecting cervical motion and increased risk of adjacent segment degeneration, pseudo arthrosis on top of the approach related complications $[4,20]$. In our described technique, we only removed the

Table 2 Pearson correlation analysis of continuous variables

\begin{tabular}{|c|c|c|c|c|c|c|c|c|}
\hline Continuous variables & & Age & SFA & $\mathrm{CCA}$ & CCL & VDL & VAS & ODI \\
\hline \multirow[t]{2}{*}{ Age } & Pearson correlation & 1 & -.432 & -.237 & -.192 & -.274 & -.067 & -.064 \\
\hline & Sig. (2-tailed) & & .170 & .208 & .310 & .143 & .725 & .738 \\
\hline \multirow[t]{2}{*}{ Sagittal foraminal area (SFA) } & Pearson correlation & -.432 & 1 & .375 & .546 & .578 & .121 & .144 \\
\hline & Sig. (2-tailed) & .170 & & .026 & .001 & .000 & .488 & .409 \\
\hline \multirow[t]{2}{*}{ 3D CT coronal area (CCA) } & Pearson correlation & -.237 & .375 & 1 & .285 & .160 & -.147 & -.093 \\
\hline & Sig. (2-tailed) & .208 & .026 & & .097 & .357 & .400 & .596 \\
\hline \multirow[t]{2}{*}{ Cranial-caudal length (CCL) } & Pearson correlation & -.192 & .546 & .285 & 1 & .446 & -.262 & -.231 \\
\hline & Sig. (2-tailed) & .310 & .001 & .097 & & .007 & .128 & .182 \\
\hline \multirow[t]{2}{*}{ Ventro-dorsal length (VDL) } & Pearson correlation & -.274 & .578 & .160 & .446 & 1 & .130 & .191 \\
\hline & Sig. (2-tailed) & .143 & .000 & .357 & .007 & & .457 & .272 \\
\hline \multirow[t]{2}{*}{ VAS improvement (VAS) } & Pearson correlation & -.067 & .121 & -.147 & -.262 & .130 & 1 & .966 \\
\hline & Sig. (2-tailed) & .725 & .488 & .400 & .128 & .457 & & .000 \\
\hline \multirow[t]{2}{*}{ NDI improvement (NDI) } & Pearson correlation & -.064 & .144 & -.093 & -.231 & .191 & .966 & 1 \\
\hline & Sig. (2-tailed) & .738 & .409 & .596 & .182 & .272 & .000 & \\
\hline
\end{tabular}

Statistical significant variables are highlighted in bold 
Fig. 7 a 43-years old female who presented with persistent right $\mathrm{C} 5$ radiculopathy who failed conservative management for 3 months underwent right C4/5 PECD. a MRI sagittal cut showing foraminal stenosis of right $\mathrm{C} 4 / 5$ with uncal hypertrophy, and protruding disc. b MRI corresponding sagittal cut after posterior endoscopic cervical foraminotomy, bony decompression performed space filled with fluid, nerve root was decompressed. c showed right $\mathrm{C} 4 / 5$ uncal hypertrophy and disc protrusion which was decompressed in the same corresponding cut in $\mathbf{d}$

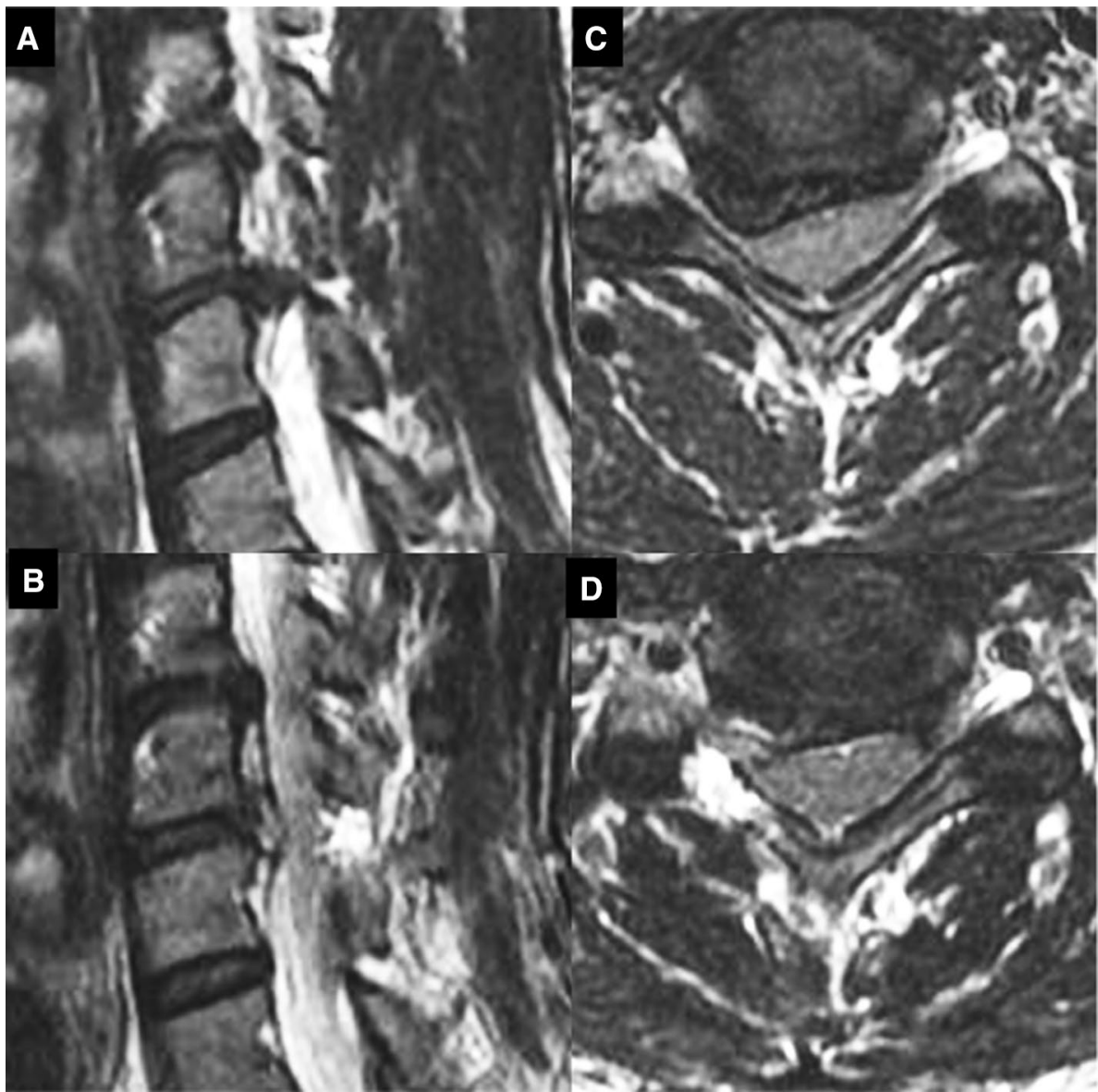

prolapsed part of the disc while preserving the majority of the cervical intervertebral disc. The conservation of cervical disc avoided the need for fusion or disc replacement procedure. It also avoided the risk of loss of disc height associated in anterior endoscopic cervical discectomy [21].

Posterior cervical foraminotomy is a motion preserving procedure which focuses directly on decompression of the soft prolapsed disc and foraminal stenosis causing cervical radiculopathy. While preservation of the neck motion by doing posterior cervical foraminotomy is advantageous to the patients, the relatively common occurrence of postoperative neck pain after posterior cervical surgery is one of the main reasons that many surgeons prefer anterior procedure over the posterior procedure in treatment of cervical radiculopathy $[11,22]$. The key strategies to prevent post-operative instability and axial neck pain are preservation of the cervical soft tissues, ligamentous structures and bony facets without compromising the ability to adequately decompress the foramen. The development of endoscopic techniques and in particular PECD technique aims to preserve posterior structures and yet achieve the similar goals of conventional posterior cervical foraminotomy [18]. Several authors in their series had been able to achieve good clinical outcomes [5, 23]. In our series, we achieved similar trend of statistically significant good clinical outcomes in NDI, VAS and MacNab's score at average 29.6 months followup. The success of the PECD relied on careful selection for appropriate patients and proper evaluations of pre-operative imaging. In our experience, the ideal indications for PECD were: (1) Patients who have significant disabling cervical radiculopathy for more than 6 weeks and failed conservative treatment strategies (2) There is concordant same level (s) and side of cervical radiculopathy with MRI finding. (3) Laterally located lesions affecting cervical nerve root are shown on axial MRI cut of the affected level(s): cervical nerve root compression should occur with $2 / 3$ bulk of the soft disc material lateral to the lateral margin of the thecal sac of the cervical cord and/or foraminal stenosis caused by uncovertebral joint hypertrophy, facet joint and lateral bulging degenerated disc. The main limitations of this technique are centrally located lesions and cervical malalignment. As cervical cord retraction is not possible by endoscope working tube, endoscope cannot gain access to central located lesion. Without possible instrumentation with PECD technique, surgeons cannot correct any cervical malalignment related neck pain and cervical radiculopathy with PECD. Therefore, the contraindications of PECD are patients who have predominant pure axial neck pain, clinical 
or radiological cervical instability, and associated myelopathy with anterior disc herniation and or calcification. Other relative contraindications are calcified disc and ossified posterior longitudinal ligaments [24, 25].

There are limited studies on radiological evaluation of foraminal dimensions after posterior cervical foraminotomy and discectomy, most of the studies focused on the preservation of disc height, range of motion of cervical spine and preservation of cervical stability, and showed good radiological results within these parameters measured [26-28]. The limitations of these clinical and radiological evaluation studies were that no comparative measurements of the foraminal dimensions to assess the status of decompression achieved.

In our study, we focused on evaluation on the foraminal parameters to investigate on how much decompression we could achieve with PECD procedure. We found that using CT scan, there was statistical significant increase in foraminal enlargement in both sagittal and coronal parameters. Determination on conventional axial cuts were made difficult due in part to the complex, oblique orientation of the cervical neuroforamen. Using 3D CT reconstruction, we increased the reliability of measurement of foraminal stenosis as compared to conventional axial CT imaging [29].

In sagittal evaluation, we found that there were more decompression in ventral to dorsal direction than cranial to caudal direction of the cervical foramen with twice the increase in foraminal measurement with the mean of, $2.1 \mathrm{~mm}$ (ventral to dorsal direction) and $1.2 \mathrm{~mm}$ (cranial to caudal direction). This was due to the close relationship of the corresponding pedicles and exiting nerve root in the cranial and caudal direction of the decompression. Good decompression was demonstrated in terms of sagittal and coronal foraminal area measurements. We observed a mean increase in $21.5 \mathrm{~mm}^{2}$ in sagittal foramen area, while there was a much wider area of decompression in medial lateral direction with mean increase in 3D CT coronal posterior area of decompression measured at $537 \mathrm{~mm}^{2}$ as compared to preoperative state.

There was a statistically significant correlations between sagittal foraminal area and all the other measured foraminal parameters such as 3D CT coronal area, ventro-dorsal length and cranial-caudal length. However, there was no statistical significant correlation between clinical outcomes with foraminal parameters. This suggested that more decompression and foraminal enlargement did not directly equate to better clinical outcomes. This is an important finding as endoscopic decompression typically requires less amount of facet destruction to achieve adequate foraminal decompression as compared to open surgery, but yet it can achieve good clinical results. However we have not managed to find the tipping point of decompression required to achieve good clinical outcomes in our study. Further research with a larger data might be required to investigate the optimal amount of bony decompression required to achieve good clinical outcomes.

In an anatomical biomechanics study performed by Raynor et al., he demonstrated that in order to decompress $5 \mathrm{~mm}$ of exit nerve root, $50 \%$ of facets were needed to be sacrificed and to decompress $8-10 \mathrm{~mm}$ of exiting nerve root, $70 \%$ of facets decompression were required. However, he also demonstrated that $70 \%$ facetectomized specimen would failed by fracture at $159 \mathrm{lb}$ but none of $50 \%$ facetectomized specimen failed at $208 \mathrm{lbs}$. Hence, the recommendation was generally to decompress less than $50 \%$ of the facet joint [30]. PECD technique performed through this choreographed stepwise approach described in the paper can help in identification of key anatomical structures checkpoints and highlighting the targets for decompression required to achieve good radiological and clinical outcomes. We had no gross instability observed in flexion and extension films taken in any of the patients who were followed up for the mean of 29.6 months. We felt that this technique could minimize soft tissue dissection as endoscope was docked directly on the $\mathrm{V}$ point of the facet which underwent foraminotomy. Bony resection was optimized by endoscopic decompression. A large percentage of the disc was preserved as only the prolapsed part of the disc was removed during the procedure. These factors might decrease the risk of postoperative instability. Although a similar comparative radiological study would be required to compare with open posterior cervical foramintomy to evaluate this theory.

The $12 \%$ complication rate of this cohort was comparable to other minimally invasive posterior cervical foraminotomy and anterior cervical discectomy and fusion literature [4, $10,31,32]$. The most common complications in the literature related to posterior cervical foraminotomy are wound issues, neuropraxia and durotomy. PECD has good potential in decreasing wound related complications due to its ability to preserve soft tissue and avoid prolonged retraction of any particular cervical muscle group due to constant mobility of endoscope [31]. Incidental durotomy can be a problem in any endoscopic or open procedure, a patch blocking repair technique for small incidental dura tear is a common strategy in treatment of endoscopic dura tear [33]. However, one needs to be careful when pushing the patch against spinal cord to avoid cord injury. We had 2 cases of neuropraxia (8\%) which was due to exiting nerve root retraction by the open beveled working cannula to facilitate discectomy. Our patients with neurapraxia did not do well in MacNab's score with one fair and one poor results. Hence, it is an important consideration to select patients who required less neural retractions during the procedure to achieve good clinical outcomes. The metanalysis by Tao et al. showed for cervical surgeries showed C5 palsy rate in ACDF (5.5\%) is lower than posterior cervical laminoplasty $(6 \%)$ and laminectomy and fusion (12.2\%). The mechanism of the nerve root palsy 
is hypothesized to be due to tethering phenomenon and acute decompression and expansion of spinal cord leads to nerve root palsy [34]. Another mechanism proposed was foraminal dimension and cord rotation [35]. However, it is controversial that foraminotomy did not predict the time or the likelihood of recovery from C5 palsy [36]. We felt that our mechanism of nerve root palsy was an issue of nerve root retraction by working cannula and not that of tethering of the nerve root. Working cannula induced neurapraxia is not a technical complication in anterior cervical surgeries, open posterior laminoplasty or laminectomy and fusion surgeries. Both the patients required no revision and had recovered their power in the nerve root involved. A more refinement of this endoscopic technique to create more subneural space by drilling on the pedicle and vertebra body to gain access to the disc would be a good consideration to circumvent this issue and minimize neural retraction might address this issue of nerve root palsy from working tube retraction [37, $38]$. We had one case of disc recurrence (4\%) from the index level occurred in our cohort which happened after 2 years from index surgery. Bydon et al. showed a reoperation rate of $9.9 \%$ in 151 patients with posterior cervical foraminotomy $60 \%$ of the revision is due to recurrence of disc herniation. The rate of same level reoperation $(6.6 \%)$ was higher than adjacent segment (1.2\%) or distant segment (1.9\%) [39]. Recurrence of disc herniation is unlikely in open anterior cervical surgery due to complete disc removal for placement of cage or artificial disc. Van Eck et al. showed in their series of 672 patients that $15 \%$ of ACDF required revision and most revisions for ACDF is for adjacent segment disease or pseudoarthrosis [40]. Martin et al. found in their cohort of 715 patients that a higher revision rate was found in cervical disc replacement (15\%) compared to ACDF (10\%) and posterior surgical procedure (5\%) in their cohort. They also found that disc replacement was not protective against adjacent segment disease [41]. Overall, there are advantages and disadvantages in terms of complications in all approaches to cervical spine, presenting in different forms. Complications of PECD is affected on steep learning curve and familiarity of endoscopic system. Hence, we felt that spine surgeon should perform PECD after being competent in lumbar decompression surgeries.

\section{Limitations of the study}

There were some inherent limitations in this study. Being a study with prospective data collection and retrospective analysis, there was inherent risk of selection bias. The authors minimized the selection bias as all cervical prolapsed disc during the study period was treated with endoscopic decompression. There was no control group comparative data as the authors had not done open posterior cervical foraminotomy nor ACDF for unilateral cervical radiculopathy during the study period. The information bias was minimized as analysis were done by orthopaedic and neurosurgery spine surgeons with endoscopic experience who did not take part in the management of the study population. Recall bias was minimized with the prospective nature of clinical data collection. Pre-operative data such as smoking history was not collected which might introduce confounders in the study. The relatively small sample of number of levels were studied which had limitations in the ability for subgroup analysis of foraminotomy and foraminotomy with discectomy. Small sample size with a medium term followup period was an inherent limitation, longer follow-up study would be desirable to evaluate the treatment effectiveness and reoperation rate in the long term. Radiological evaluation used in this study was a novel method we used with no validation data available for similar surgical techniques.

\section{Conclusion}

Uniportal posterior endoscopic cervical foraminotomy and discectomy is a safe, efficient and precise choreographed set of technique in the treatment of cervical radiculopathy. It significantly improved clinical outcomes and achieved the objective of increasing in the cervical foramen size in our cohort of patients.

Acknowledgements We would like to acknowledge scientific team members Ms Jae Eun Park, Ms Elin Lee and Mr Kyeong Rae Kim for providing assistance in statistical support, acquiring full text articles and managing digital works.

Funding No benefits in any form have been or will be received from a commercial party related directly or indirectly to the subject of this manuscript.

\section{Compliance with ethical standards}

Conflict of interest All co-authors have no conflict of interest.

Ethical approval All procedures performed in studies involving human participants were in accordance with the ethical standards of the Nanoori Hospital's Ethics Committee and the national research committee and with the 1964 Helsinki declaration and its later amendments or comparable ethical standards.

Informed consent Informed consent was obtained from all individual participants included in the study.

Consent from patients All patients had given their informed consent for photographs, videos and images for publication.

Open Access This article is licensed under a Creative Commons Attribution 4.0 International License, which permits use, sharing, adaptation, distribution and reproduction in any medium or format, as long as you give appropriate credit to the original author(s) and the source, provide a link to the Creative Commons licence, and indicate if changes were made. The images or other third party material in this article are included in the article's Creative Commons licence, unless indicated 
otherwise in a credit line to the material. If material is not included in the article's Creative Commons licence and your intended use is not permitted by statutory regulation or exceeds the permitted use, you will need to obtain permission directly from the copyright holder. To view a copy of this licence, visit http://creativecommons.org/licenses/by/4.0/.

\section{References}

1. Woods BI, Hilibrand AS (2015) Cervical radiculopathy: epidemiology, etiology, diagnosis, and treatment. J Spinal Disord Tech 28:E251-259. https://doi.org/10.1097/bsd.0000000000000284

2. Wong JJ, Cote P, Quesnele JJ, Stern PJ, Mior SA (2014) The course and prognostic factors of symptomatic cervical disc herniation with radiculopathy: a systematic review of the literature. Spine J 14:1781-1789. https://doi.org/10.1016/j.spine e.2014.02.032

3. Richards O, Choi D, Timothy J (2012) Cervical arthroplasty: the beginning, the middle, the end? Br J Neurosurg 26:2-6. https:// doi.org/10.3109/02688697.2011.595846

4. Epstein NE (2019) A review of complication rates for anterior cervical diskectomy and fusion (ACDF). Surg Neurol Int 10:100. https://doi.org/10.25259/sni-191-2019

5. Selvanathan SK, Beagrie C, Thomson S, Corns R, Deniz K, Derham C, Towns G, Timothy J, Pal D (2015) Anterior cervical discectomy and fusion versus posterior cervical foraminotomy in the treatment of brachialgia: the Leeds spinal unit experience (20082013). Acta Neurochir 157:1595-1600. https://doi.org/10.1007/ s00701-015-2491-8

6. Lee DG, Park CK, Lee DC (2017) Clinical and radiological results of posterior cervical foraminotomy at two or three levels: a 3-year follow-up. Acta Neurochir 159:2369-2377. https://doi. org/10.1007/s00701-017-3360-4

7. Papavero L, Kothe R (2018) Minimally invasive posterior cervical foraminotomy for treatment of radiculopathy: an effective, timetested, and cost-efficient motion-preservation technique. Oper Orthopad und Traumatol 30:36-45. https://doi.org/10.1007/s0006 4-017-0516-6

8. Kim M, Kim HS, Oh SW, Adsul NM, Singh R, Kashlan ON, Noh JH, Jang IT, Oh SH (2019) Evolution of spinal endoscopic surgery. Neurospine 16:6-14. https://doi.org/10.14245/ns.18363 22.161

9. Ye ZY, Kong WJ, Xin ZJ, Fu Q, Ao J, Cao GR, Cai YQ, Liao WB (2017) Clinical observation of posterior percutaneous full-endoscopic cervical foraminotomy as a treatment for osseous foraminal stenosis. World Neurosurg 106:945-952. https://doi.org/10.1016/j. wneu.2017.07.085

10. Komp M, Oezdemir S, Hahn P, Ruetten S (2018) Full-endoscopic posterior foraminotomy surgery for cervical disc herniations. Oper Orthop und Traumatol 30:13-24. https://doi.org/10.1007/s0006 4-017-0529-1

11. Jodicke A, Daentzer D, Kastner S, Asamoto S, Boker DK (2003) Risk factors for outcome and complications of dorsal foraminotomy in cervical disc herniation. Surg Neurol 60:124-129. https:// doi.org/10.1016/s0090-3019(03)00267-2

12. Haefeli M, Elfering A (2006) Pain assessment. Eur Spine J 15(Suppl 1):S17-S24. https://doi.org/10.1007/s00586-005-1044-x

13. Fairbank JC, Pynsent PB (2000) The oswestry disability index. Spine 25:2940-2952. https://doi.org/10.1097/00007632-20001 1150-00017

14. Macnab I (1971) Negative disc exploration. an analysis of the causes of nerve-root involvement in sixty-eight patients. J Bone Joint Surg Am 53:891-903
15. Suzuki A, Daubs MD, Inoue H, Hayashi T, Aghdasi B, Montgomery SR, Ruangchainikom M, Hu X, Lee CJ, Wang CJ, Wang BJ, Nakamura H (2013) Prevalence and motion characteristics of degenerative cervical spondylolisthesis in the symptomatic adult. Spine 38:E1115-1120. https://doi.org/10.1097/BRS.0b013e3182 9 b1487

16. Quillo-Olvera J, Lin G-X, Kim J-S (2018) Percutaneous endoscopic cervical discectomy: a technical review. Ann Transl Med 6:100-100. https://doi.org/10.21037/atm.2018.02.09

17. Kim JH, Adsul N, Kim HS, Choi SH, Kim KJ, Jang J-S, Jang I-T (2018) Safety and efficacy of endoscopic posterior cervical discectomy and foraminotomy using three-point plaster traction technique. J Minim Invasive Spine Surg Tech 3:23-26. https://doi. org/10.21182/jmisst.2017.00241

18. Chang JC, Park HK, Choi SK (2011) Posterior cervical inclinatory foraminotomy for spondylotic radiculopathy preliminary. J Korean Neurosurg Soc 49:308-313. https://doi.org/10.3340/ jkns.2011.49.5.308

19. Song Z, Zhang Z, Hao J, Shen J, Zhou N, Xu S, Ni W, Hu Z (2016) Microsurgery or open cervical foraminotomy for cervical radiculopathy? A systematic review. Int Orthop 40:1335-1343. https://doi.org/10.1007/s00264-016-3193-4

20. Storm PB, Chou D, Tamargo RJ (2002) Surgical management of cervical and lumbosacral radiculopathies: indications and outcomes. Phys Med Rehabil Clin N Am 13:735-759. https://doi. org/10.1016/s1047-9651(02)00014-1

21. Bucknall V, Gibson JA (2018) Cervical endoscopic spinal surgery: a review of the current literature. J Orthop Surg 26:2309499018758520. https://doi.org/10.1177/2309499018 758520

22. Kimura A, Shiraishi Y, Inoue H, Endo T, Takeshita K (2018) Predictors of persistent axial neck pain after cervical laminoplasty. Spine 43:10-15. https://doi.org/10.1097/brs.0000000000002267

23. Ruetten S, Komp M, Merk H, Godolias G (2008) Full-endoscopic cervical posterior foraminotomy for the operation of lateral disc herniations using 5.9-mm endoscopes: a prospective, randomized, controlled study. Spine 33:940-948. https://doi.org/10.1097/ BRS.0b013e31816c8b67

24. Witzmann A, Hejazi N, Krasznai L (2000) Posterior cervical foraminotomy: a follow-up study of 67 surgically treated patients with compressive radiculopathy. Neurosurg Rev 23:213-217. https://doi.org/10.1007/p100011957

25. Peto I, Scheiwe C, Kogias E, Hubbe U (2017) Minimally invasive posterior cervical foraminotomy: freiburg experience with 34 patients. Clin Spine Surg 30:E1419-e1425. https://doi. org/10.1097/bsd.0000000000000517

26. Kwon Y-J (2014) Long-term clinical and radiologic outcomes of minimally invasive posterior cervical foraminotomy. J Korean Neurosurg Soc 56:224-229. https://doi.org/10.3340/ jkns.2014.56.3.224

27. Zhang C, Wu J, Xu C, Zheng W, Pan Y, Li C, Zhou Y (2018) Minimally invasive full-endoscopic posterior cervical foraminotomy assisted by o-arm-based navigation. Pain Physician 21:E215-e223

28. Youn MS, Shon MH, Seong YJ, Shin JK, Goh TS, Lee JS (2017) Clinical and radiological outcomes of two-level endoscopic posterior cervical foraminotomy. European Spine J 26:2450-2458. https://doi.org/10.1007/s00586-017-5017-7

29. Schell A, Rhee JM, Holbrook J, Lenehan E, Park KY (2017) Assessing foraminal stenosis in the cervical spine: a comparison of three-dimensional computed tomographic surface reconstruction to two-dimensional modalities. Glob Spine J 7:266-271. https ://doi.org/10.1177/2192568217699190

30. Richard BR, James P, Ilan S (1985) Cervical facetectomy and its effect on spine strength. J Neurosurg 63:278-282. https://doi. org/10.3171/jns.1985.63.2.0278 
31. Sahai N, Changoor S, Dunn CJ, Sinha K, Hwang KS, Faloon M, Emami A (2019) Minimally invasive posterior cervical foraminotomy as an alternative to anterior cervical discectomy and fusion for unilateral cervical radiculopathy: a systematic review and meta-analysis. Spine 44:1731-1739. https://doi.org/10.1097/ brs.0000000000003156

32. Skovrlj B, Gologorsky Y, Haque R, Fessler RG, Qureshi SA (2014) Complications, outcomes, and need for fusion after minimally invasive posterior cervical foraminotomy and microdiscectomy. Spine J 14:2405-2411. https://doi.org/10.1016/j.spine e.2014.01.048

33. Kim HS, Raorane HD, Hung WP, Heo DH, Sharma SB, Jang IT (2020) Incidental durotomy during endoscopic stenotic lumbar decompression (ESLD): incidence, classification and proposed management strategies. World Neurosurg. https://doi. org/10.1016/j.wneu.2020.01.242

34. Wang T, Wang H, Liu S, Ding W-Y (2017) Incidence of C5 nerve root palsy after cervical surgery: a meta-analysis for last decade. Medicine 96:e8560-e8560. https://doi.org/10.1097/MD.00000 00000008560

35. Jack A, Ramey WL, Dettori JR, Tymchak ZA, Oskouian RJ, Hart RA, Chapman JR, Riew D (2019) Factors associated with C5 palsy following cervical spine surgery: a systematic review. Glob Spine J 9:881-894. https://doi.org/10.1177/2192568219874771

36. Zach P, Daniel L, Erick MW, Ahmed AK, Jeff E, Matthew LG, Sheng-Fu L, Timothy FW, Ali B, Nicholas T, Daniel MS (2019) Time to recovery predicted by the severity of postoperative C5 palsy. J Neurosurg Spine 32:191-199. https://doi. org/10.3171/2019.8.SPINE19602

37. Tong Y, Huang Z, Hu C, Fan Z, Bian F, Yang F, Zhao C (2020) A comparison study of posterior cervical percutaneous endoscopic ventral bony decompression and simple dorsal decompression treatment in cervical spondylotic radiculopathy caused by cervical foraminal and/or lateral spinal stenosis: a clinical retrospective study. BMC Musculoskelet Disord 21:290-290. https://doi. org/10.1186/s12891-020-03313-2

38. Kim HS, Wu PH, Lee YJ, Kim DH, Kim JY, Lee JH, Jeon JB, Jang IT (2020) Safe route for cervical approach: partial pediculotomy, partial vertebrotomy approach for posterior endoscopic cervical foraminotomy and discectomy. World Neurosurg. https ://doi.org/10.1016/j.wneu.2020.05.033

39. Mohamad B, Dimitrios M, Mohamed M, de la Rafael G-R, Daniel MS, Timothy FW, Jean-Paul W, Ziya LG, Ali B (2014) Longterm patient outcomes after posterior cervical foraminotomy: an analysis of 151 cases. J Neurosurg Spine 21:727-731. https://doi. org/10.3171/2014.7.SPINE131110

40. van Eck CF, Regan C, Donaldson WF, Kang JD, Lee JY (2014) The revision rate and occurrence of adjacent segment disease after anterior cervical discectomy and fusion: a study of 672 consecutive patients. Spine 39:2143-2147. https://doi.org/10.1097/ brs.0000000000000636

41. Skeppholm M, Henriques T, Tullberg T (2017) Higher reoperation rate following cervical disc replacement in a retrospective, longterm comparative study of 715 patients. Eur Spine J 26:24342440. https://doi.org/10.1007/s00586-017-5218-0

42. Xiao CM, Yu KX, Deng R, Long QY, Chu L, Xiong Y, Sun B, Chen L, Yan ZJ, Deng ZL (2019) Modified K-hole percutaneous endoscopic surgery for cervical foraminal stenosis: partial pediculectomy approach. Pain Physician 22:E407-e416

Publisher's Note Springer Nature remains neutral with regard to jurisdictional claims in published maps and institutional affiliations.

\section{Affiliations}

\section{Pang Hung Wu ${ }^{1,2}$ (D) Hyeun Sung Kim ${ }^{1}(\mathbb{D})$ Yeon Jin Lee ${ }^{1} \cdot$ Dae Hwan Kim ${ }^{1} \cdot$ Jun Hyung Lee ${ }^{1} \cdot$ Kyung-Hoon Yang $^{1}$. Harshavardhan Dilip Raorane ${ }^{1} \cdot$ II-Tae Jang ${ }^{1}$}

1 Department of Neurosurgery, Nanoori Hospital Gangnam, 731, Eonju-ro, Gangnam-gu, Seoul, Republic of Korea
2 Department of Orthopaedic Surgery, Juronghealth Campus, National University Health System, Singapore, Singapore 